\title{
Literature and insights Editorial
}

\section{True or false}

I am sure that people outside the auditing profession sometimes regard its members as overly critical types, prone to suspicion about information that is needed to verify financial and management accounting reports. This is especially so when they have to access papers and electronic files for taxation audits in order to substantiate income and expenses. The audits themselves can be seen as an intrusion on normal business too. On the other hand, we know that independent scrutiny can be vital, and that standards for doing so regulate these processes.

There is a wider issue than that, however, and areas where investigative reporters become our proxy auditors.

With an increasing culture of doubt, public mistrust is growing regarding information and news reports, particularly when bias and self-interest might (or do) lie behind them. That applies frequently these days in politics, product marketing and administrative propaganda. In politics, we might query the timing of the news, or its extent/limitations, or the motivation behind its release, for instance. There could also be selective omissions and editorialising involved that skew interpretation and lead to inappropriate decisions.

To extrapolate [...] Would you be content for labels on supermarket products to restrict the information needed for you to properly understand how much sugar is in your food, and its effects? Would you settle for limited knowledge of the reliability and life-span of solar panels meant to reduce your electricity bills? Do you want politicians to disclose the facts about how proposed changes to management and use of public water resources will cut drinking water to a community, and before it is too late?

Manipulation and expectations of belief are commonly at the heart of all this. And, yes, one person's truth is another's lies. One person's data is another's "fake news".

All of this is by way of a preamble to considering different aspects of working with data in order to mislead an audience for personal gain, or at least being slipshod about it. In some cases of poorly conducted scientific research, data might be sifted to argue for strong relationships and proof of a hypothesis that is formulated retrospectively. One case, according to Stephanie M. Lee, concerns Cornell University Professor Brian Wansink, who is said to have "won fame, funding, and influence for his science-backed advice on healthy eating [and] hacked and massaged low-quality data into headline-friendly studies to 'go virally big time"' (Lee, 2018). Pursuit of funding, which is becoming more critical to surviving as an academic these days, might stand out here for a lot of readers.

Does a free market work to reveal lies? Not always, and sometimes the deceits have done their work before the truth is discovered. Here, further critiquing of Wansink's papers led to many of them being retracted and he eventually resigned his position at Cornell (Rosenberg and Wong, 2018).

Accounting, Auditing \& Accountability Journal (AAAJ) welcomes submissions of both research papers and creative writing. Creative writing in the form of poetry and short prose pieces is edited for the Literature and Insights Section only and does not undergo the refereeing procedures required for all research papers published in the main body of $A A A J$. Author guidelines for contributions to this section of the journal can be found at: www.emeraldgrouppublishing.com/products/journals/author guidelines.htm?id=aaaj

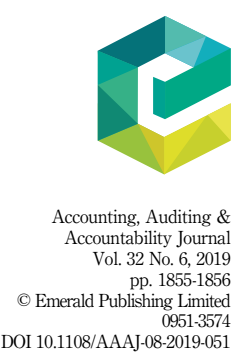


For creative insights into the uses of data, this issue contains two works: one is by 32,6 Maria Vouis, a polyglot qualified in Music, Education, Psychology and English; and, the other is a Co-Authored effort from Ann Martin-Sardesai and Lyn Daff who have experienced the effects of chasing university funding. Maria's poem is a satirical take on our increasing immersion in and reliance on electronic sources of information, often without sufficient questioning, and written after the Cambridge Analytica debacle. It is all the more resonant since it comes from a devout Christian ready to frame her poem with a tongue-in-cheek reference to a familiar prayer. That might give pause to some but it underlines its purpose, highlighting the need to find a critical and well-considered approach to the information with which we are bombarded. What stands scrutiny is worth knowing. Ann and Lyn's poem confronts the issue of metrics, the quest for research work results that accrue respect and government recognition through rankings and, ultimately, funds. Is this a case of the tail wagging the dog?

Steve Evans

School of Humanities \& Creative Arts, Flinders University, Adelaide, Australia

\section{References}

Lee, S.M. (2018), "Sliced and diced: the inside story of how an Ivy League food scientist turned shoddy data into viral studies", Buzzfeed, 26 February, available at: www.buzzfeed.com/stephaniemlee/ brian-wansink-cornell-p-hacking?utm_term=.akmAZG4N4\#.tw22XB7o7

Rosenberg, E. and Wong, H. (2018), "This Ivy League food scientist was a media darling. He just submitted his resignation, the school says", The Atlantic, 20 September, available at: www. washingtonpost.com/health/2018/09/20/this-ivy-league-food-scientist-was-media-darling-nowhis-studies-are-being-retracted/?noredirect=on\&utm_term=.61a5c30fca37 